\title{
ALGUMAS CONSIDERAÇÕES SOBRE AS CRÍTICAS AO CONHECIMENTO CIENTÍFICO MODERNO NO CONTEXTO DO PROCESSO EDUCATIVO E A TEMÁTICA AMBIENTAL
}

\author{
Luciano Fernandes Silva * \\ Edson do Carmo Inforsato **
}

\begin{abstract}
Resumo: Este trabalho aponta algumas críticas feitas ao conhecimento científico moderno no âmbito do movimento ambientalista, com especial destaque às idéias filosóficas cartesianas. Entendendo ser o processo educativo uma etapa fundamental para amenizar ou reverter o quadro de degradações ambientais, analisamos al guns limites dessas críticas como a não contextualização histórico-social de tais idéias. Por fim observamos a inadequação que causa a repetição dessas críticas à ciência moderna para o processo educativo.
\end{abstract}

Unitermos: Temática ambiental ; processo educativo; cartesianismo.

Abstract This paper points out some criticism done to the modern scientific knowledge within the environmental movement, specially emphasizing the Cartesian philosophic ideas. We consider the educational process as a fundamental stage to diminish or even to revert the scenery of environmental degradations. Some limits of such criticism are analyzed, namely, the historical-social non-contextual shaping of such ideas. Finally, we focus the inadequacy that causes the repetition of such criticism to the modern science for the educational process.

Keywords: Environmental issues, educational process, cartesianism

\section{Introdução}

Verifica-se em várias regiões do mundo uma mobilização cada vez maior de dife rentes grupos da sociedade que procuram reconhecer, entender e reverter o processo instalado de uma crise ambiental.

O simples reconhecimento do problema já é um grande passo, pois a degradação ambiental não se iniciou em períodos recentes, mas é decorrência de ações que vêm ocorrendo através da história. Basta tomar o exemplo de registros feitos sobre uma série de alterações ambientais que causaram uma insalubridade pública nas cidades medievais. Portanto, tornase um equívoco afirmar que somente agora existem problemas ambientais.

Talvez 0 que seja recente, isto sim, é a tentativa e a iniciativa de se entender as causas que levaram 0 homem a degradar 0 ambiente em que vive. $N$ esta empreitada vários aspectos devem ser considerados : os sistemas econômicos desenvolvidos em cada sociedade; os valores éticos presentes na relação homem e natureza; 0 desenvolvimento

\footnotetext{
* Programa de PósG raduação em Educação Escolar, Faculdade de Ciências Letras, U niversidade Estadual Paulista, UNESP - Campus de Araraquara (email: lufesilva@uol.com.br).

** Professor Assitente D outor, Departamento de Didática, Faculdade de Ciências e Letras, Universidasde Estadual Paulista, U NESP - Campus de Araraquara (email: tamoyo@fdar.unesp.br).
} 
tecnológico; a explosão populacional; os dogmas religiosos; as determinações políticas que interessam somente a pequenos grupos e, mesmo, uma discussão filosófica mais ampla sobre mudanças de paradigma.

0 reconhecimento e o entendimento dos problemas ambientais não bastam; há uma procura em se desenvolver algumas ações que possam reverter ou mesmo minimizar o quadro de crise instalado. Porém, fica bem claro que nenhuma dessas ações sozinha consegue equacionar uma situação complexa como essa.

Acompanhando as preocupações destacadas pela sociedade, algumas pessoas e instituições começaram a pensar na contribuição do processo educativo para ajudar atenuar ou mesmo reverter o quadro de desequilíbrios instalados. Entre os educadores envolvidos com a temática ambiental há um aparente consenso sobre a forma de se abordar o trabaIho educativo que tenha por objetivo analisar e criticar o quadro de degradação ambiental existente. Este trabalho deve ir além dos aspectos técnicos e considerar também os aspectos sociais e políticos envolvidos. Tais temas resgatam uma visão ampla dos problemas ambientais que não ficam restritos aos elementos naturais do meio ambiente, mas também envolvem os elementos construídos e todos os aspectos sociais, culturais, econômicos e políticos inter-relacionados. Uma boa evidência desta forma de se abordar a temática ambiental pode ser encontrada nos parâmetros curriculares do ensino fundamental, nos quais o tema é apresentado como transversal. Pretende-se, deste modo, um trabal ho educativo interdisciplinar envolvendo o tema "M eio Ambiente".

D e acordo com a abordagem mencionada, o trabalho com a temática ambiental em sala de aula deve oferecer algo mais do que as informações sobre 0 ambiente físico e biológico. U ma grande contribuição para este trabalho é enfocar a concepção e a história da ciência ou, de modo mais amplo, a natureza do conhecimento científico e suas implicações para 0 modo como o homem reconhece e se relaciona com a natureza.

0 aprofundamento a respeito da concepção de natureza dentro do conhecimento científico pode ajudar a entender e apontar caminhos para a solução dos diversos problemas ambientais, já que eles vêm se tornando um foco importante para trabalhar o ensino das ciências físico-naturais na escola. N este sentido, é importante uma reflexão a respeito de algumas críticas que vêm sendo feitas ao processo de produção do conhecimento científico.

$M$ uitas vezes o tratamento dado aos fundadores da ciência moderna, vem no sentido de acusá-los de muitos dos males presentes em nossa sociedade. Copérnico, Galileu, D escartes, Bacon e N ewton são os cientistas e filósofos mais citados e criticados por estes autores (Ferry, 1992, G onçal ves, 1998, Grün, 1996). 0 entendimento de al gumas questões de ordem filosófica é importante para se localizar dentro do contexto dessas críticas. É também importante para que tenhamos atitudes críticas diante de textos que abordam esta temática, pois a simples repetição de outros argumentos pode ser prejudicial no discurso educacional, uma vez que, ao se falar e se repetir tais argumentos sem 0 devido cuidado, reforça-se a tendência em se 'demonizar' a ciência e seus grandes filósofos. R ossi (1989) destaca em seu texto que muitos autores procuram apresentar ao grande público uma imagem totalmente negativa da ciência e da sociedade industrial, numa verdadeira onda anticientificista. Chama a atenção também que: 
A recusa de todo tipo de conhecimento científico e racional do mundo juntou-se a um apaixonado requisitório contra a modernidade: daí nasceram uma identificação da modernidade com o diabólico, o vulgar, o absolutamente negativo; uma reivindicação da subjetividade como lugar da salvação; um profetismo vago, ameaçador e moralístico, incapaz de previsões (Rossi, 1989, p. 13)

Portanto, perguntamos: Até que ponto estes argumentos levam em consideração o ambiente sociohistórico em que viveram estes grandes cientistas e filósofos? É o conhecimento científico por si mesmo o causador de grandes catástrofes?

Este trabalho não tem a intenção de responder questões de ordem tão complexa, mas achamos conveniente considerar algumas críticas que estão sendo feitas dentro do movimento ambientalista, para poder explorá-las com mais cuidado considerando contexto educativo.

A seguir, vamos localizar al gumas das críticas mais difundidas sobre a ciência moderna e seus fundadores, com especial destaque para o cientista e filósofo francês René D escartes. D epois, tentaremos contrapor estas críticas com as questões acima levantadas.

\section{Críticas à ciência moderna e aos seus fundadores}

Destacaremos as críticas ao pensamento cartesiano, por ser Descartes apontado como o desencadeador de algumas práticas "não ambientais". Grüm (1996) analisa que é impossível dentro do pensamento cartesiano, trabalhar com os questionamentos levantados pela temática ambiental, uma vez que tal pensamento se sustenta na separação homem e natureza. D e acordo com o autor:

0 problema metodológico enfrentado por D escartes é o seguinte: se existe uma unidade da razão, deve haver algo que necessariamente não seja uno e portanto, seja divisivel. Estealgo éo mundo, a natureza, tornada objeto da razão. A conseqüência disso équea razão só pode legitimar sua autonomia como divisora do mundo físico. A razão cartesiana pressupõe a divisibilidade infinita do objeto" (G rüm, 1996, p.35).

Para Ferry (1992), Descartes representa o pensador que distinguiu tão bem os homens dos animais que acabou considerando os últimos como máquinas. Ao enfatizar tal distinção ele diz que:

A natureza é, para nós, letra morta. No sentido exato: ela não nos fala mais porque deixamos há muito tempo - desde D escartes, pelo menos - de Ihe atribuir alma e de a crer habitada por forças ocultas. (Ferry, 1992, p. 14-15)

Gonçalves (1989) também caracteriza o pensamento cartesiano como causador da separação do homem da natureza. 0 autor destaca que com o método cartesiano, o homem pode enfim dominar a natureza etorna-se, por assim dizer, o "..senhor e possuidor desta..." (Gonçalves, 1989, p. 41), utilizando este conhecimento para os fins que desejar. Para o autor, a separação homem e natureza se processa através da divisão feita por D escartes entre espírito e matéria. 
D a mesma maneira G rüm (1996) destaca que estas idéias pressupõem o afastamento e diferenciação do homem da natureza. A natureza torna-se, assim, objeto do seu estudo e sujeita a toda e qualquer manipulação. $N$ as suas palavras:

Se a razão é autônoma, a natureza não pode sêlo. Então, a natureza precisa ser dominada. A questão é simples: Como posso dominar alguma coisa da qual faço parte? A resposta é que não posso fazer parte da natureza. Se pretendo dominá-la, preciso me situar fora dela (Grüm, 1996, p. 35).

Para algo qualificar-se como humano é preciso a máxima distinção possível da natureza. Este autor expressa argumentos que mostram os reflexos das idéias cartesianas de separação homem e natureza na educação. D estaca ainda que existe nos currículos escolares uma total separação en tre o ambiente humano e natural, uma alusão ao projeto da "autonomia cartesiana" em curso.

Portanto, todos os textos acima destacados criticam severamente as idéias cartesianas. Trabalharemos com algumas dessas críticas, mas tentaremos resgatar o momento em que D escartes viveu e desenvolveu suas idéias. D estacaremos o cenário sociohistórico em que a ciência moderna, que naquele momento nascia, estava envolvida, e 0 ambiente cultural da Europa daquele momento.

\section{C ontexto sociohistórico das idéias de D escartes}

$\mathrm{H}$ á um consenso histórico de que a I dade M édia tenha se caracterizado pelo predomínio de um certo obscurantismo, evidenciado pelos argumentos irrefutáveis da I greja, a crença em poderes sobrenaturais de mágicos, bruxas e videntes e um temor das forças "ocultas" da natureza.

M as o século XVI surge trazendo novas idéias, sendo estas marcadas pela promoção de profundas transformações na visão de mundo do homem. Podemos destacar algumas delas, como: Copérnico argumenta que a Terra não seria o centro do U niverso e que - Sol deveria ocupar este lugar; Kepler, utilizando-se das anotações de Tycho Brahe, concebe órbitas elípticas para os planetas; G alileu observa com seu telescópio as luas de Júpiter e argumenta contra o discurso da incorruptibilidade do céu.

Estes poucos exemplos mostram como algumas concepções de mundo anteriormente aceitas foram contestadas. Tais concepções estavam profundamente ligadas à filosofia aristotélica, e esta filosofia servia de base para muitos argumentos da religião católica. 0 mundo até então ocupava o glorioso centro do universo, os céus eram o lugar da incorruptibilidade, ou seja, nada mudaria nunca. As órbitas celestes eram então imaginadas em círculos perfeitos, pois este era o movimento permitido para os astros na filosofia aristotélica.

A ciência moderna que surgiu neste momento se caracterizava pelo método experimental e matemático. Porém, este método ainda carecia de argumentos filosóficos que legitimassem este pensamento. Estava clara a necessidade de se estabelecer um novo campo filosófico, no qual a ciência moderna poderia enfim ter um caminho certo a seguir. 
N este contexto do final do século XVI nasceu René D escartes, natural da França de Luiz XII, de família burguesa e educado em colégio jesuíta.

D escartes não conseguiu romper sua ligação com o contexto histórico-cultural da sua época e certamente suas idéias estavam impregnadas da influência do pensamento judaico-cristão. $\mathrm{H}$ avia ainda o temor de ser desaprovado pela I greja C atólica, e isso não era bemvindo, os exemplos de Giordano Bruno e $G$ alileu eram mais do que significativos. Como destaca Rossi (1992), o cardeal Roberto Belarmino faz circular por toda a Europa em julho de 1614 que:

$N$ ão se cansando os heréticos e os inimigos(...) de semear continuamente os seus erros e heresias no campo da Cristandade com tantos e tantos livros perniciosos que se publicam todo dia, é necessário não cochilar, mas efforçar-se por extirpá-los pelo menos daqueles lugares que podemos (Rossi, 1992, p. 91).

Estes exemplos representavam parte do cenário do final do século XVI e início do século XVII. É interessante discutir os argumentos e idéias de D escartes a partir deste enfoque sóciohistórico.

D escartes estava profundamente preocupado com a confusão em que se encontrava o pensamento científico de sua época. Ele compreendia que não era suficiente pesquisar e resolver enigmas científicos, era preciso legitimar a própria ciência. 0 pensamento científico estava muito disperso e era confundido com outros conhecimentos, como o pensamento escolástico, caracterizado por discussões sem fim; com os dogmas que se confundiam com as verdades científicas e mesmo com o pensamento religioso.

O s argumentos científicos, em muitas ocasiões, buscavam na interpretação das escrituras sagradas a legitimação da nova visão do mundo. Em Rossi (1992) podemos encontrar 0 seguinte trecho, sobre as dúvidas de Galileu em conciliar seus argumentos com o das Escrituras:

Os filósofos naturais, enquanto leitores e intérpretes do livro da natureza que é escrito por $D$ eus, não devem também indicar aos intérpretes da Escritura aqueles "sentidos" que concordam com a verdade natural? (Galileu, apud Rossi, 1992, p. 97)

Galileu chegava mesmo a considerar que a Bíblia continha a verdade copernicana. Rossi (1992) destaca esta argumentação de G alileu, que encontra na “...passagem de Josué e dos versículos do Salmo 18..." o trecho do livro sagrado que confirma as teses copernicanas.

Certamente Galileu estava muito preocupado em não ser punido pela I greja, mas ele também era um homem que não tinha argumentos filosóficos necessários para legitimar a ciência moderna. D entro desta confusão entre a interpretação da escritura sagrada e da natureza, existia também a convicção na maioria desses cientistas na existência de um $D$ eus. Um exemplo é a crença de Galileu em um D eus racional que escreveu o mundo em linguagem matemática. Conforme Rossi (1992): 
As imagens platônicas de um mundo com estruturas matemáticas e raci onais, de um D eus geómetra que compõe o mundo numero, podere et mensura, serão sem dúvida maisfecundas, no desenvolvimento da astronomia e da física moderna... (Rossi, 1992, p. 204).

D escartes também pressupunha a existência de D eus (criador e organizador do universo), mas ele foi buscar um método rigoroso e livre de influências religiosas, para que as certezas pudessem ser encontradas. $M$ as onde buscar este rigor? 0 centro de referência será a própria razão.

No início Descartes de tudo duvidava. Argumentava em seu texto "D iscurso do M étodo" que nada havia no mundo que não pudesse ser refutado ou ser uma ilusão. D escartes chegava a pensar que mesmo ele podia não existir. Tudo no mundo poderia fazer parte de uma trama diabólica de um ser maligno que tudo inventava e iludia simplesmente para se divertir. M as qual seria então a primeira certeza, para dela poder partir para outras? D escartes chegou à conclusão de que a única certeza que havia no mundo era o seu pensamento:

$M$ as logo depois atentei que, enquanto queria pensar assim que tudo era falso, era necessariamente preciso que eu, que o pensava, fosse alguma coisa. $E$, notando que eta verdade - Penso, logo existo - era tão firme e tão certa que todas as mais extravagantes suposições dos cépticos não eram capazes de a abalar, julguei que podia admiti-la sem escrúpulo como o primei ro princípio da filosofia que buscava.

D epois, examinando atentamenteo queeu era evendo que podia fingir quenão tinha nenhum corpo e que não havia nenhum mundo, nem lugar algum onde eu existisse, mas que nem por isso podia fingir que não existia; e que, pelo contrário, pelo próprio fato de eu pensar em duvidar da verdade das outras coisas, decorria muito evidentemente e muito certamente que eu existia; ao passo que, se apenas eu parasse de pensar, ainda tudo o mais imagi nara fosse verdadeiro, não teria razão alguma de acreditar que eu existisse; por isso reconheci que eu era substância, cuja única essência ou natureza épensar, eque, para existir, não necessita denenhum lugar nem depende, de coisa alguma material. D e sorte que ete eu, isto é, a alma pela qual sou o que sou, éinteiramente distinta do corpo, e até mais fácil de conhecer que ele, e, mesmo se 0 corpo não existisse, ela não deixaria de ser tudo o que é. (D escartes, 1996, p. 38-39)

D escartes encontrava a primeira certeza: Penso, logo existo e dela podia enfim partir para outras. É importante destacar que o pensamento rigoroso que D escartes (1996) procura pela razão, segue pela via do pensamento matemático. Para ele, este era o único pensamento (caracterizado por números e figuras) que poderia ser concebido da mesma maneira por todos os que dele se utilizassem.

Procurava então D escartes dar a seus argumentos uma base filosófica para a ciência moderna que nascia naquele momento. D urante muito tempo eles foram valiosos para garantir um contexto sólido para se trabalhar com a ciência moderna. 0 mundo, representado por 
estes argumentos, era distinto da natureza humana, ou seja, o homem poderia desmontar 0 Universo e entender e classificar suas partes, para depois montá-lo novamente. $D$ iferente, por exemplo, da filosofia oriental que não permitia o estudo da natureza por considerá-la esta "divina" e estar preenchida de al gum elemento sagrado. Estando a natureza livre de qual quer essência humana, esta poderia então ser estudada.

U ma observação necessária é que muitos destes argumentos são válidos ainda hoje. D evemos ter a precaução de procurar entender se o pensamento cartesiano causa realmente muitos obstácul os à temática ambiental ou se são al gumas das interpretações deste pensamento que dificultam o trabal ho dos ambientalista.

A seguir tentaremos argumentar algumas posições que temos a este respeito.

\section{0 pensamento cartesiano e a problemática ambiental}

Diversos autores destacam três pontos principais do pensamento cartesiano que contribuiriam para a existência da crise ambiental. U m deles diz respeito ao tre cho no qual Descartes (1996) mencionava que o homem deve tornar-se o senhor da nature za. 0 outro faz referência ao problema do Cogito cartesiano, no qual argumenta-se que houve a separação do sujeito e do objeto. 0 último refere-se à metodologia de dividir o objeto de estudo em quantas partes forem possíveis, com reflexos no campo do saber científico em disciplinas estanques e incomunicáveis.

Q uanto ao primeiro argumento, que diz respeito ao modo como D escartes (1996) teria argumentado a favor do domínio da natureza pelo homem e do seu utilitarismo, encontramos no capítulo 6 do texto "Discurso do M étodo" o seguinte trecho:

...elas me mostraram que é possivel chegar a conhecimentos muito úteis à vida, e que, ao invés dessa filosofia especulativa ensinada nas escolas, podese encontrar uma filosofia prática, mediante a qual, conhecendo a força e as ações do fogo, da água, do ar, dos astros, dos céus e de todos os outros corpos que nos rodeiam, tão distantemente como conhecemos os diversos ofícios de nossos artesãos, poderíamos empregá-las do mermo modo em todos os usos a que são adequadas e assim nos tornamos como que senhores e professores da natureza...I sso é de desejar não somente para a invenção de uma infinidade de artifícios que nos fariam usufruir, sem trabalho algum, os frutos da terra e de todas as comodidades que nela se encontram... (D escartes, 1996, p. 69)

Este trecho nos remete de volta ao contexto sóciohistórico em que $D$ escartes vive. Diante da possibilidade de poder direcionar a ciência moderna através de um caminho seguro, ele espera que o homem possa colher os frutos deste bom caminho. 0 outro conhecimento, que ele criticava, é representado pela escola. E esta ensinava a "filosofia especulativa", alusão clara ao pensamento da escolástica que impedia qualquer recurso à experiência, que como sabemos caracterizava-se pelo predomínio das idéias de Aristóteles, as que embasavam as doutrinas da I greja Católica. Parecenos que D escartes buscava uma compreensão próxima da verdade do que realmente seria a natureza, e este conhecimento deveria ser útil para o bem-estar 
do homem. A natureza tão inóspita e cruel para o homem do seu tempo poderia enfim ser dominada e ficar livre de todo o ocultismo que despertava temores.

Certamente $D$ escartes não imaginava que o homem do distante século $X X$ poderia conseguir tanto conhecimento e técnicas ao ponto de poder exterminar por completo florestas e animais.

$\mathrm{N}$ ão estamos desqualificando, com isto, todas as críticas feitas pelos autores contemporâneos. Porém é importante observar que as preocupações e as conseqüentes formulações de idéias e pensamentos de $D$ escartes eram respostas dadas às solicitações do seu tempo. A interpretação que damos hoje àquela passagem não é a mesma que possa ter existido naquele momento histórico do século XVII. É importante que perguntemos qual a interpretação que existe hoje do trecho acima de $D$ escartes e a quem tem servido este modo de pensar. $D$ evemos trabal har para que haja integração entre fato e valor, ética e objetividade no pensamento científico. M orin (1998) afirma em seu texto que a ciência é sem consciência e que esta ausência de responsabilidade do pesquisador perante à sociedade e o homem acabam por determinar a manipulação do conhecimento científico pelos Estados e pelos conglomerados econômicos. Brügger (1994) destaca em seu texto que:

A ciência cartesiana tem portanto limites estruturais na medida em que muitos problemas enfrentados pela sociedade requerem soluções políticas (e aqui adentramos novamente 0 delicado terreno da Ética) e não "científicas' ou técnicas. (Brügger, 1994, p. 117)

N um ensaio magistral sobre a agonia da nossa civilização, Gusdorf (1978) refere-se à retomada dos val ores nos empreendimentos humanos, particularmente àqueles relacionados à ciência. Diz ele:

A ciência e a técnica de origem humana, não são nem humanas, nem desumanas, elas são indiferentes, neutras e 0 homem deve se defender cuidadosamente de deixála escapar ao seu controle ( Gusdorf, 1978, p.96).

M ais adiante ele enfatiza ao dizer que:

A ciência recente nos ensinou e ensina a cada dia muitas coisas sobre os planetas próximos e distantes, sobre a Lua, o Sol, M arte, Vênus, as estrelas e as galáxias longínquas. D o ponto de vista da astronomia, a Terra é um astro entre todos os astros que povoam o espaço cósmico. M as acontece que a Terra é o lugar da humanidade, e isto Ihe dá aos nossos ol hos um valor consi derável. M arte eV ênus são domíni os da verdade, tanto quanto a Terra; mas a Terra é a nossa morada e, pois, sua verdade se reveste a nossos ol hos de uma importância incomparável. O s cienti stas estão sempre tentados a se perder no espaço cósmico, que não reconhece localização privilegiada. 0 papel do filósofo no tempo presente é, sem duvida, o de anunciar a necessidade da volta à Terra; à revolução galileana, que se despediu do mundo humano, deve suceder 0 
movimento compensador da revolução não-gali leana, que sem rejeitar as aquisições das ciências e das técnicas, afirme o primado da exigência da humanidade sobre as fascinações da inteligibilidade científica e as perigosas miragens da potência técnica. 0 retorno à Terra seria a empresa de reconstituir 0 C osmos, não o Cosmos antigo da astrobiologia, mas um Cosmos $\mathrm{N}$ ovo cujo princípio seria a vontade de renovar a aliança das verdades e dos valores. (Gusdorf, 1978, p. 97)

Podemos concluir a partir daí que o pensamento cartesiano, e todo o pensamento científico, é refém do fato de que sua utilização leva em conta fatores econômicos, sociais e políticos. 0 u seja, o homem está sempre buscando o conhecimento, mas o modo como este conhecimento é utilizado pelos cientistas e pela sociedade diz respeito aos valores éticos, estéticos e políticos. Esta esfera do conhecimento humano não deveria estar desvinculada da esfera do pensamento científico. Toda atividade científica é uma atividade humana e como tal pode tanto ser direcionada para o bem como para o mal. A principal ausência no texto de D escartes (1996) é a argumentação sobre esses valores, mas isto não inviabiliza o pensamento cartesiano. N ecessitamos complementá-lo, sem esquecer que se o homem não houvesse 'dominado' as forças da natureza inóspita, estaríamos refém dela e talvez o conhecimento científico que temos não teria alcançado o lugar de destaque que tem hoje. Brügger (1994) afirma que:

É importante ressaltar que o paradigma cartesiano-newtoniano não está errado. Cada teoria é válida em relação a uma certa gama de fenômenos e, com isso, 0 que importa é estarmos ciente de sua limitações. (Brugger, 1994, p.116)

Com referência ao Cogito cartesiano encontramos muitos autores criticando o suposto início de um projeto de separação do homem e natureza. Vejamos um trecho tirado da obra de D escartes:

$M$ as logo depois atentei que, enquanto queria pensar assim que tudo era falso, era necessariamente preciso que eu, que o pensava, fosse al guma coisa. $E$, notando que esta verdade - Penso, logo existo - era tão firme e tão certa que todas as mais extravagantes suposi ções dos cépti cos não eram capazes de abalar, julguei que podia admiti-la sem escrúpulo como o primeiro princípio da filosofia que buscava. (D escartes, 1996, p. 38)

Já tivemos a oportunidade de nos referir ao contexto sóciohistórico no qual estas idéias foram engendradas. É importante ainda salientar que o pensamento racional-empirista foi e continua sendo muito útil para a ciência. Com a distinção do objeto de pesquisa e o cientista podendo se ver fora da natureza, como se estivesse dirigindo o ol har para uma fotografia, foi possível caminhar em diversas áreas, como na física e na química. A natureza livre de qualquer essência humana pode ser estudada. U m exemplo importante é que podemos dissecar e estudar o corpo humano, estando este sem vida, pois o que é essencialmente humano (talvez uma alma) já não esteja mais ali. Este corpo que agora faz parte da natureza e pode ser manipulado. 
Q uanto ao último trecho que destacamos do livro de D escartes (1996), o autor relata que em seu método o objeto deve ser dividido em quantas partes forem necessárias. N esta passagem, os críticos do autor destacam que este modo de pensar trouxe a especialização em excesso com reflexos nítidos na disciplinarização da ciência. Argumenta-se ainda que este modo de pensar dificulta o trabalho inter e transdisciplinar, que o movimento ambientalista aponta como o mais indicado para práticas educativas relacionados com a temática ambiental.

Repetimos mais uma vez aqui as críticas levantadas e ainda observamos que a divisibilidade do objeto foi e continua sendo importante para a ciência. 0 método cartesiano de divisão do objeto em partes simples, vem facilitar 0 entendimento e 0 estudo, porém, este modo de pensar possui limites. M orin (1998) analisa que hoje precisamos de um pensar complexo. No seu entendimento necessitamos levar em conta em nossos estudos, a parte e 0 todo. $N$ ão é possível entender as partes sem conhecer 0 todo e 0 inverso também, não é possível conhecer o todo sem conhecer as partes. 0 trecho abaixo de M orin (1998) sintetiza esta idéia:

...cada uma de nossas células, até mesmo a mais modesta célula da epi derme, contém a informação genética do ser global. (É evidente que só há uma pequena parte da informação expressa nessa célula, ficando o resto inibido.) N esse sentido, podemos dizer que não só a parte está no todo, mas que o todo etá na parte. (M orin, 1998)

Concluímos assim, que as idéias de D escartes são válidas ainda hoje, inclusive para um trabal ho educativo em sala de aula, porém existem possibilidades e limites para o trabal ho educativo com estas idéias. 0 modelo científico do método cartesiano não postula dar todas as respostas, e afinal, a ciência não trabalha com verdades absolutas. 0 conhecimento de hoje é simplesmente aquele que mais se aproxima de uma interpretação histórica possível da natureza, dentro de um determinado contexto social.

D iante desta conclusão podemos enfim analisar as críticas ao pensamento científico moderno dentro de um contexto educativo.

\section{As críticas ao conhecimento científico moderno e o contexto do processo educativo}

As idéias cartesianas, apesar dos muitos limites a ela impostos, são válidas ainda hoje para a ciência. Podemos dizer o mesmo a respeito das idéias de Copérnico, G alileu e N ewton, estando estes entre aqueles mais criticados pelo movimento ambientalista.

Será que o professor no contexto educativo do trabal ho em sala de aula deveria simplesmente afirmar que D escartes 'foi um homem ruim que iniciou o processo de devastação ambiental', ou que, 'a concepção de universo mecânico newtoniana foi a causadora de todos os males existentes em nossa sociedade?

Já estaríamos satisfeitos se durante o processo educativo o professor tivesse melhores condições (de formação, de material didático, tempo e salário) de trabalhar as idéias da ciência moderna de forma clara. $\mathrm{O}$ u seja, seria muito importante conhecer minimamente 0 
que representam e o que significaram as idéias desses grandes cientistas e qual sua relação com o nosso contexto histórico, econômico, político e social.

As teorias de $\mathrm{N}$ ewton, que se aproximam muito da realidade dentro de um limite específico, não são ainda compreendidas pela maioria dos nossos alunos, e isto é válido também para as órbitas elípticas de Kepler, os conceitos mecânicos de Galileu e mesmo a configuração planetária de Copérnico.

Ao abordar a natureza da ciência durante o processo educativo, temos que ter o devido cuidado de não criticar, sem embasamento teórico, o conhecimento científico, mesmo porque não temos nada melhor para colocar no lugar dele. 0 que os críticos mais ferrenhos do conhecimento científico moderno fazem é oferecer teses obscuras de um conhecimento que não consegue se estruturar. É sempre necessário considerar o ambiente sócio-histórico em que as idéias desses grandes cientistas foram criadas e que responderam satiffatoriamente às necessidades da época.

Levando em consideração esses poucos cuidados, o professor pode estar contribuindo para lutar contra 0 analfabetismo científico muito presente entre nossos alunos. Analfabetismo que está presente também em respostas simples e redentoras encontradas em parte do movimento ambientalista. N ão existe um caminho simples que possa resolver os problemas ambientais, mas o trabalho educativo pode e deve oferecer sua parcela de contribuição.

\section{Referências bibliográficas:}

BRÜ GGER, P. Educação ou adestramento ambiental? Letras Contemporâneas, 1994. DESCARTES, R . D iscurso do método. São Paulo, M artins Fontes, 1996. FERRY, L. A N ova ordem ecológica: a árvore, o animal, o homem. São Paulo, s. n., 1994. (Ensaios)

GRÜ N , M . Ética e educação ambiental: a conexão necessária. São Paulo, Papirus, 1996.

GON ÇALVES, C.E.P. Os (des)caminhos do meio ambiente. São Paulo, Contexto, 1998.

GÜSD O RF, G . A agonia da nossa civilização . São Paulo, Convívio, 1978.

M ORIN , E. Ciência com consciência. Rio de Janeiro, Bertrand Brasil, 1998.

ROSSI, P. A ciência e a filosofia dos modernos. São Paulo, Eddunesp, 1989. 